ISSN: $1980-055 X$

\title{
VALORAÇÃO AMBIENTAL: UMA ABORDAGEM TEÓRICA DAS RELAÇỐES ENTRE OS ESTUDOS CLIMATOLÓGICOS E AS ANÁLISES ECONÔMICAS ${ }^{1}$
}

\author{
Lays Regina Andriucci e João Lima Sant'Anna Neto ${ }^{3}$
}

\begin{abstract}
RESUMO
Este artigo apresenta um levantamento de pesquisas feitas tanto para o arcabouço climático como para o econômico. Retrata desta maneira, uma aproximação teórica do tema clima versus economia. Para os levantamentos teóricos da climatologia, a base utilizada é dos estudos de variabilidade, principalmente da temperatura e precipitação. Para a economia, a abordagem apóia-se em alguns estudos iniciais de valoração ambiental. Após, discute-se alguns autores que consideram a aproximação da analise ambiental à econômica. Por meio deste trabalho, observa-se que a valoração ambiental é uma corrente da economia ambiental que visa auxiliar no processo de integração das questões ambientais no sistema econômico. Entendendo, que pela forma como a sociedade capitalista é fundamentada, ser de grande importância à apresentação de estudos que considerem ou inter-relacionam os dois objetos.
\end{abstract}

Palavras-chave: Clima, Economia, Variabilidade, Correlação, Cidade

\section{ENVIRONMENTAL VALUATION: A THEORETICAL APPROACH OF THE RELATIONS BETWEEN CLIMATOLOGICAL STUDIES AND ECONOMIC ANALYSIS}

\begin{abstract}
This paper presents a survey about researches done under the climatic scope and the economic one also. It figures out this way, a theoretical approach to the theme climate versus economy. For the theoretical surveys of climatology, the base is studies about variability, mainly on temperature and precipitation. For the economy, the approach is supported by some initial studies on environmental valuation. Finally, it is discussed some authors that take in account the approach on environmental analysis into the economic. By means of this work, it is noticed that environmental valuation is a trend in the environmental economy in order to help in the integration process in the environ-
\end{abstract}

\footnotetext{
${ }^{1} \mathrm{O}$ artigo apresentado é fundamentado em um dos capítulos da Dissertação de Mestrado intitulada "Análise da Influência Termo-Pluviométrica nos Indicadores do Comércio de Maringá (PR): Um Ensaio Metodológico na Perspectiva da Valoração Ambiental", orientada pelo prof. Dr. João Lima Sant'Anna Neto, defendida em 2003, pela FCT/UNESP.

${ }^{2}$ Doutoranda do Curso de Pós-Graduação em Geografia FCT/UNESP - e-mail: andriucci02@yahoo.com.br.

${ }^{3}$ Prof. Dr. do Departamento de Geografia da FCT/UNESP - Grupo de Pesquisa "Climatologia Geográfica" (CNPq). E-mail: joaolima@fct.unesp.br.
} 
mental questions of the economic system. By understanding in what way capitalistic society is set up, is important to the introduction of studies taking into account or inter-relating these two objects.

Key-words: Climate; Economy; Variability; Correlation; City.

\section{Introdução}

Este estudo justifica-se tendo como relevância dois aspectos principais: um ambiental, que sob a perspectiva geográfica é de grande relevância para o próprio suprimento da vida humana; além de, na ótica de nosso modelo desenvolvimentista, que tiveram historicamente grandes dificuldades de serem efetivamente respeitado; o outro econômico, onde nas discussões mais atuais entre os profissionais da área econômica, é visto que, embora o uso dos recursos ambientais não tenha seu preço reconhecido no mercado, seu valor econômico existe, na medida que seu uso altera o nível de produção e consumo (bemestar) da sociedade.

Nas últimas décadas é possível constatar um aumento de interesse dos pesquisadores da área econômica para o meio ambiente. Esse, crescente interesse acompanha o grande desenvolvimento das cidades, ou seja, alto índice de concentração de pessoas e também uma crescente utilização dos recursos ambientais (infelizmente sem planejamento). Os efeitos da poluição urbana são bastante relevantes, particularmente para as economias industrializadas nas quais uma parcela maior da população se concentra nessas áreas. $\mathrm{E}$, se a referência for feita especificadamente para o Brasil, constata-se que nos últimos 50 anos tivemos uma das economias de crescimento mais rápidas do mundo. Mas, apesar desse crescimento contínuo, não se tem reduzido as desigualdades sociais no mesmo ritmo. Observa-se que durante os anos 80 e no início desta década as pressões inflacionárias prejudicaram as oportunidades de crescimento do Brasil e aumentaram os conflitos sociais.

O Brasil, até recentemente, baseava o seu modelo de desenvolvimento na substituição de importações, ou seja, o protecionismo, a criação de empresas estatais e grandiosos programas de incentivos fiscais, gerando uma grande transformação na economia que anteriormente era agrária em uma sociedade com um grau de industrialização bastante alto.

No entanto, estas transformações econômicas foram afirmadas em um período de tempo bastante curto, o que gerou grandes problemas na estrutura econômica do país. Segundo Motta (2004) o Brasil tem aplicado políticas de estabilização monetária que reduziram a taxa de inflação mensal de $80 \%$ para $1 \%$. Mas, o sucesso não foi tão impressionante com a agenda social. A perspectiva de crescimento em curto prazo é difícil de prever e a crescente taxa de desemprego torna ainda maiores os problemas sociais.

Baseando-se nos dados apresentados pelo Ministério do Meio Ambiente (MMA, 2004), observa-se que atualmente no país já estão sendo tomadas atitudes para diminuir as diferenças sociais, reduzir os problemas ambientais, ou 
seja, promover diante de um mundo globalizado, um país não só com um crescimento econômico isolado, mas o desenvolvimento deste como um todo.

Torna-se interessante afirmarmos ainda que para o MMA, sem dúvida, hoje, existe um consenso quanto às dificuldades da gestão ambiental. Os atuais problemas podem, contudo, ser classificados em três categorias principais: a primeira seria as baixas provisões orçamentárias face aos altos custos de gerenciamento; a segunda, políticas indutoras de perdas ambientais; e a terceira, questões de eqüidade que dificultam o cumprimento da lei. Sistematizando assim, é mais fácil compreender que se tem uma clara situação que requer a introdução econômica na gestão ambiental ${ }^{4}$.

Desta forma, considera-se que a valoração ambiental é uma corrente da economia ambiental que visa auxiliar no processo de integração das questões ambientais no sistema econômico. Sendo o clima de inquestionável valor para a manutenção da vida no planeta, o desafio é inseri-lo no contexto da valoração ambiental. Assim, o presente artigo tem como finalidade apresentar um levantamento teórico onde relaciona alguns autores tanto da área especifica da climatologia, quanto da economia ambiental. Sendo este, mais um auxilio nas bases teóricas para pesquisas que tem como intuito encontrar possíveis influências do clima na sociedade, especificadamente no âmbito econômico.

\section{Abordagem Climatológica}

\section{A Climatologia no Brasil}

Constata-se que até meados da década de 1960, as pesquisas climatológicas brasileiras não tinham como objeto principal o enfoque dinâmico do clima. Assim, sempre enfatizando as descrições (método separativo), as pesquisas referentes à gênese climática, à ação do clima e sua repercussão na sociedade, não eram tidas como preocupações primordiais. Os ideais de ruptura das pesquisas deterministas e separatistas ocorreram, principalmente, pelas contribuições de Sorre (1951). Ele rompe com a idéia determinista que havia anteriormente, partindo para uma nova concepção de climatologia, definindo o clima como a série de estados atmosféricos sobre um lugar na sua sucessão habitual e compreendendo a climatologia como geográfica (SORRE,1951). A partir de Sorre dois grandes pesquisadores Pedelaborde (França) e Monteiro (Brasil) passam a ser o referencial das pesquisas no ramo da Climatologia.

Pedelaborde demonstrou uma grande preocupação em estudar os tipos de tempo (ou fazer a síntese dos tipos de tempo). Monteiro (1976, p.30) afirmou que:

[...] Para Pedelaborde o paradigma (que certamente não é o estado médio da atmosfera, o que o aproxima de Sorre), seria a 'totalidade dos tipos de tempo', para mim é o ritmo, ou seja, o encadeamento, sucessivo e contínuo, dos estados atmosféricos e suas articulações no sentido de retorno aos mesmos estados.

${ }^{4}$ Sendo interessante afirmar também, que esta noção do papel do critério econômico está longe de ser inovadora e está cada vez mais difundida em outros países. 
Monteiro conseguiu compreender e implementar os novos paradigmas propostos por Max Sorre, percebendo que a abordagem (climatológica) somente alcança o nível geográfico, quando na análise, são colocados os tipos de tempo em seqüência contínua (não importando a escala anos-padrão e sazonal).

Monteiro (1971) apresentou também um grande trabalho, mostrando ser a análise rítmica (importância - conceitos - metodologias) capaz de revolucionar a pesquisa da climatologia brasileira.

Segundo Monteiro (1971, p.04):

[...] O conceito de 'ritmo', expressão da sucessão dos estados atmosféricos, conduz, implicitamente, ao conceito de 'habitual' pois que há variações e desvios que geram diferentes graus de distorções até atingir padrões 'extremos'.

A variação anual constatada através das variações mensais dos elementos climáticos é a maneira pela qual, primeiramente, pode ser percebida a noção de ritmo. E, para compreender como é dada a noção de regime, deve-se fazer repetição das variações mensais em vários e sucessivos anos (MONTEIRO,1971).

Monteiro (1971, p.09) considerou também que:

[...] Apenas a partir da escala diária é possível associar à variação dos elementos do clima os tipos de tempo que se sucedem segundo os mecanismos da circulação regional. Associando-se, nesta escala, a variação de todos os elementos, concomitantemente, a interpretação é sobremodo enriquecida pelo dinamismo de que se reveste. A partir daquele estudo temos continuado a desenvolver este tipo de representação que consideramos fundamental à análise climatológica.

Outra constatação, destacada por Monteiro (1971, p.12) é de que:

[...] Só a análise rítmica detalhada ao nível de 'tempo', revelando a gênese dos fenômenos climáticos pela interação dos elementos e fatores, dentro de uma realidade regional, é capaz de oferecer parâmetros válidos à consideração dos diferentes e variados problemas geográficos desta região.

Após Monteiro, surgiram vários trabalhos buscando compreender o ritmo climático, como: Guadarrama (1971) - analisou a relação do ritmo pluvial e a produção de arroz no Estado de São Paulo; Tarifa (1973) - analisou os tipos de tempo e o balanço hídrico no extremo oeste paulista; Titarelli (1972) - fez uma relação do frio de abril de 1971 (a partir da análise rítmica), com os impactos no ambiente geográfico; Zavatini (1983) - analisou as variações do ritmo pluvial no norte do Paraná e no oeste de São Paulo; Sant'Anna Neto (1990) - investigou as chuvas na Zona Costeira Paulista e o ritmo climático; entre outros.

\section{Variabilidade Climática}

Compreendendo a importância do clima e suas repercussões na organização do espaço, devem ser destacados estudos que identifiquem a variabilida- 
de climática. Somente através da compreensão de tal comportamento, será possível compreender a influência exercida pelo clima na sociedade.

Assim, o ato de mudar, ser diverso, apresentar-se sob diversas formas ou aspectos, ser inconstante e/ou mudar de direção, pode ser dentre muitas definições, uma das maneiras de melhor explicar o significado de variabilidade.

Essas variações climáticas são inconstâncias, atribuídas a diversos fatores. A agitação constante da atmosfera é uma delas. Na atmosfera...

[...] não existem simples processos unidirecionais de causa e efeito, uma vez que os efeitos freqüentemente retornam para alterar suas causas. Assim, as mudanças dentro da atmosfera podem ser internamente induzidas dentro do sistema Terra atmosfera ou externamente induzidas por fatores extraterrestres (AYOADE, 1988, p.205).

Um dos pontos de divergências científicas no debate do aquecimento global está ligado aos mecanismos de retroalimentação feedbacks, que envolvem a água nos seus três estados físicos, e suas possíveis influências no clima da Terra. É importante lembrar que o significado retroalimentação abrange tanto o ato de ampliar como atenuar uma perturbação inicial. No primeiro caso, é dita positiva, e, no segundo, negativa. Qualquer modelo de clima global tem de lidar com muitos mecanismos de retroalimentação simultaneamente. Considerar esses mecanismos de forma isolada pode levar a resultados diferentes, e até mesmo opostos (CUNHA,2003).

Deve-se observar que o dióxido de carbono $\left(\mathrm{CO}_{2}\right)$, o ozônio $\left(\mathrm{O}_{3}\right)$ e o vapor d'água $\left(\mathrm{H}_{2} \mathrm{O}\right)$ são compostos que auxiliam no equilíbrio energético da Terra. Assim, quando ocorre variação nesses elementos, esse equilíbrio energético global é afetado, podendo também ser constatado algum tipo de conseqüência na circulação geral da atmosfera.

A variabilidade que ocorre no clima não pode ser atribuída apenas a circulação da atmosfera. O clima envolve também a hidrosfera, biosfera, litosfera e criosfera que formam (juntamente com a atmosfera) o sistema climático, além da complexidade de fatores cósmicos (manchas solares, ciclo lunar, etc.).

Ayoade (1988, p.205) afirmou também que o clima depende de dois fatores principais:

1- a natureza dos componentes que formam o sistema climático e as interações entre vários componentes;

2- a natureza das condições geofísicas exteriores ao sistema climático e as influências que exercem sobre o sistema climático.

$\mathrm{E}$ considera que [...] O estado climático em qualquer período dado depende de três fatores cruciais:

1- A quantidade de energia proveniente do sol percebida pelo sistema climático;

2- A maneira pela qual esta energia é distribuída e absorvida sobre a superfície da Terra;

3- A natureza da interação dos processos entre os vários componentes do sistema climático: 
As teorias de mudança climática tentam explicar as variações temporais dos três fatores acima. Contudo, as variações no clima ocorrem em diferentes escalas de tempo e, portanto, podemos requerer diferentes teorias para explicar tais variações. Esta é a razão pela qual nenhuma teoria isolada de mudança climática seja considerada satisfatória na explicação de todas as variações ocorridas no clima mundial. Além disso, acredita-se que vários outros fatores atuam para causar uma mudança no clima.

Nas pesquisas feitas em relação à variabilidade climática, foi possível perceber que cada pesquisador enfatiza uma determinada categoria de análise, que melhor explique os motivos da variabilidade climática. Por exemplo, tendo como objeto de estudo a variabilidade pluviométrica, destacam-se, entre outros, os seguintes autores:

-Blanco e Godoy (1967): tiveram como metodologia à análise das normais, utilizando os postos pluviométricos de São Paulo, Minas Gerais, Mato Grosso e Paraná;

-Aldaz (1971) e Azevedo (1974): caracterizaram o regime das chuvas no Brasil, mostrando a circulação atmosférica e a variabilidade pluviométrica.

Sant'Anna Neto (2000): investigou a variabilidade climática dando ênfase às diversidades pluviais no Estado de São Paulo.

Para este autor:

[...] A sucessão de anomalias pluviométricas que ocasionam de modo dramático as secas no Nordeste, as cheias do Brasil Meridional, as enchentes nas áreas metropolitanas associadas a uma caótica infra-estrutura urbana, as geadas e precipitações de granizo nas lavouras do Centro-Sul, as chuvas intensas que provocam deslizamentos e movimentos coletivos dos solos nas encostas abruptas do Planalto Atlântico, agravados pelo desmatamento acelerado das matas úmidas de encostas são, apenas, alguns exemplos de fatos que em princípio revelam-nos um conjunto de acontecimentos excepcionais, mas que, em última análise, resultam do próprio caráter dinâmico dos fenômenos naturais, particularmente daqueles originados na atmosfera.

Em áreas tropicais, as chuvas assumem tanto o papel de destaque na compreensão do clima, em escalas regionais como podem ser consideradas como o principal elemento de análise na organização e no planejamento territorial e ambiental, em função do elevado grau de interferência, impacto e repercussão no tempo e no espaço. (SANT'ANNA NETO, 2000, pp.95-96).

Abreu (2000) investigou as mudanças globais através da implantação dos MCGAs - Modelos de Circulação Geral da Atmosfera. O já referido autor (2000, pp.84,87) apresentou que "[...] Esses modelos descrevem a atmosfera globalmente, utilizando equações matemáticas para prescrever as leis físicas que regem a atmosfera [...]". Também mostrou que "[...] Uma vez definido [...] o [...] padrão para o modelo, pode-se, então, avaliar seu uso em previsões climá- 
ticas e em estudos futuros visando simular possíveis mudanças climáticas naturais ou antrópicas que possam afetar nossa região".

Uma outra forma de análise da variabilidade climática é a relação que pode ser feita entre ela e os processos erosivos. Esse tipo de estudo, feito por Sudo (2000, pp.137-138), mostra como exemplo, dados pluviométricos referentes ao Estado de São Paulo dos últimos 50 anos:

[...] Percebe-se que está em curso uma modificação na dinâmica distributiva das precipitações pluviométricas caracterizada por chuvas mais concentradas nos meses de verão e um período de inverno menos chuvoso e mais longo, além de uma mudança nos meses de ocorrências. Isso tem reflexos no balanço hídrico do solo e, por conseguinte, no comportamento hidrológico dos cursos d'água. Desse modo, para o estudo das condições de umidade ou de sequidão climática é de fundamental importância considerarmos, além dos totais mensais e anuais das precipitações pluviométricas, o período e a freqüência com que ocorrem essas precipitações. Não menos importante é o conhecimento do comportamento da evaporação/evapotranspiração como fenômeno de transferência de água do solo para a atmosfera a partir de superfícies líquidas livres conjuntamente com a transpiração das plantas (SUDO, 2000,pp.137-138).

Assim, mesmo em meio às dificuldades, especialmente no que se refere aos acessos aos dados climáticos, a pesquisa da climatologia no Brasil está se desenvolvendo grandemente. Nas últimas décadas, houve um acentuado aumento nas discussões relacionadas a problemas ambientais. $\mathrm{E}$, somado ao avanço nas pesquisas climatológicas (especialmente pela utilização do método da análise rítmica), constatou-se cada vez mais a importância do clima como recurso necessário e influenciador nos diferentes segmentos sociais (agricultura, indústria, cidade, entre outros) e naturais (vegetação, hidrologia, solos, etc).

\section{Abordagem Econômica}

\section{A Economia Ambiental Neoclássica}

A relação existente entre economia e meio-ambiente até recentemente, era praticamente ignorada pelos economistas e ambientalistas. Os economistas sempre se posicionaram em relação ao ambiente natural, como um mero fornecedor de insumos auxiliador na manutenção do sistema. Conforme Mueller:

Até fins da década de 1960, o mainstream da teoria econômica, de tradição neoclássica, não reconhecia que problemas ambientais pudessem, sistematicamente, interferir no funcionamento eficiente de mercado. No começo deste século, Pigou (1932) chegou a oferecer elementos para análise desse tipo de falhas, que denominou 'externalidades', entretanto conforme mostram Ayres e Kneese (1969, 282-283), as externalidades ambientais eram tratadas como exceções (MUELLER, 2000c, p.2). 
Para o sistema econômico, o ambiente natural era uma fonte inesgotável de insumos materiais e de energia, nunca sobraria resíduos indesejáveis, e tudo poderia ser convertido pelo sistema. Idéia válida também na categoria de consumo. Acreditava-se que tudo o que fosse importado da natureza pertencia automaticamente a alguém, podendo ser transionados em mercados competitivos. A visão é de que a economia era um sistema isolado (fechado/autocontido), e cabia a ela explicar os fluxos de valor de troca que circulava em seu interior (empresas e famílias).

Deve-se observar que problemas ambientais levaram a acentuação do interesse dos economistas pelo ambiente natural. Exemplos, como o alto índice de problemas causados pela poluição nas grandes cidades (problemas respiratórios, inversão térmica, entre outros); a crise do petróleo em 1970; o relatório do Clube de Roma em 1972; contribuíram, entre outras coisas, para o fortalecimento da preocupação com o meio ambiente. No ano de 1987, o Relatório da Comissão Brundtland, feito pela Comissão Mundial do Meio Ambiente e desenvolvimento (CMMD), posicionou-se, não de forma alarmista, mas bastante racionalizada, perante os acontecimentos que envolviam o meio natural. Questões como o desenvolvimento sustentável e problemas gerados com o crescimento desigual entre países, passaram a ser discutidas pela sociedade.

Nesse contexto, a cidade passou a ser destaque em muitas pesquisas, já que é considerada um ecossistema criado pelo homem e necessita para a sua manutenção, extrair energia de ecossistemas naturais segundo suas necessidades. Moran (1994, p.373) considerou que:

[...] Visto que importam os alimentos e a energia de que necessitam de áreas remotas, os habitantes das cidades não vêem as conseqüências ambientais de suas demandas. Até muito pouco tempo atrás, as cidades utilizavam as áreas naturais circunjacentes como depósitos para o lixo urbano. Somente com a escalada da urbanização e da revolução nas comunicações é que essa política foi reconsiderada. Embora não tenham sido estabelecidas relações causais, as dimensões das formas de desorganização do sistema, a patologias das grandes aglomerações, e a níveis de poluição que ameaçam sua existência. Parte desse problema é a própria complexidade dos ecossistemas urbanos.

É interessante observar que atualmente existem várias evidências de uma crise crescente (referindo-se aos impactos ambientais), no entanto, poucos compreendem a seriedade dessa ameaça.

Deve-se considerar que as atitudes contidas da economia diante do meio-ambiente podem justificar-se apenas enquanto era reduzida a escala da mesma. A partir do momento em que há um aumento do requerimento de materiais e de energia para auxiliar no desenvolvimento da economia, é que se registrou os primeiros esforços para alterar as bases de análise. Especialmente na década de 60, começa a ser percebido que o fator externalidades ambientais é parte normal dos processos econômicos.

Segundo Mueller (2000c, p.2), os estudos pioneiros de mais destaque nesse contexto são: 
Ayres e Kneese (1969); Keneese, Ayres e d'Arge (1970); de Noll e Trijonis (1971); Tietenberg (1973) e de Müler (1974). Estes inovaram ao considerar a economia como um sistema que obtém do meio-ambiente materiais a serem transformados no processo produtivo bem como a energia para proporcionar essas transformações; e que devolve esses materiais a essa energia ao meio-ambiente na forma de resíduos e rejeitos.

Vários estudiosos, preocupados com a questão relacionada entre economia e meio ambiente, acreditam ser de suma importância a análise referente ao conceito de externalidade. Por isso, é muito comum encontrar autores que formulem um conceito referente.

Martin (1999) afirmou que externalidades englobam todos os efeitos da atividade econômica, positivas e negativas. Sendo que os mais comuns são os impactos negativos (ou seja, isso não impede de haver registros de impactos positivos).

Segundo Pereira (1999, p.12), a partir dessas questões foi registrado o aparecimento de correntes como a Economia da Sobrevivência (MUELLER, 1998a); Economia da Poluição (PEARCE e TURNER, 1990, capítulos 4 e 13); e Economia Ecológica (DASGUPTA,1996).

Desta forma os pesquisadores passaram a seguir por dois caminhos: a teoria neoclássica da poluição e a teoria dos recursos naturais.

Mueller (2000c), ao analisar a teoria neoclássica da poluição, faz referência principalmente a modelos estatísticos de equilíbrio geral competitivo. Considera problemas ...

...decorrentes do despejo no ecossistema de rejeitos pelo processo de produção e de consumo, apoiadas em modelos de equilíbrio geral, na linha da teoria das externalidades de Pigou (1932). (MUELLER 2000c,pp.03-04).

É bastante pertinente, destacar que a economia ambiental sempre procura responder a algumas questões, como: o sistema econômico provoca quais tipos de danos ambientais?; Para o controle da poluição e de outras formas de degradação, quais os custos e benefícios?; Quais as metodologias existentes que a sociedade possui com a finalidade de proteger o meio-ambiente? Conforme Mueller:

A teoria dos recursos naturais preocupa-se com as formas de extração dos recursos naturais pelo sistema econômico. E como na teoria da poluição, procura em suas análises responder algumas questões como, por exemplo: Para o uso de recursos naturais específicos, qual seria o padrão ótimo? Na realidade da limitada disponibilidade de alguns recursos naturais, o que deve estabelecer limites físicos ao crescimento econômico? (MUELLER, 2000c)

As questões apresentadas são apenas exemplos de inquietações que economistas neoclássicos possuem. Essas indagações podem ser analisadas na escala local (o microeconômico), bem como na escala global (agregado). 


\section{Controvérsias consideradas da abordagem ambiental neoclássica}

Mueller (2000c, p.67) considerou que a economia ambiental neoclássica "[...] se apóia em hipótese ambiental fraca atenuada [...]". Isso significa que o sistema econômico posiciona-se passivamente diante da degradação ambiental. Os agentes econômicos escolhem o grau de degradação mais apropriado (baseando em suas preferências (funções - utilidades) e custos).

Segundo Pereira (1999, p.15):

[...] em seu clássico artigo de 1967, Krutilla aduz que, ainda que se desenvolva um mercado para os bens ambientais, tal mercado será extremamente imperfeito em função da impossibilidade de se ter pleno conhecimento dos ecossistemas, da impossibilidade de se definir os potenciais interessados nos ditos bens, que muitas vezes são de interesse global e não apenas local; e do fato provável de que o pagamento pelos bens não revele o verdadeiro valor em função dos efeitos não antecipados que a preservação ambiental pode trazer.

Um outro problema é o fato da teoria neoclássica da poluição não colocar em primeiro plano alguns impactos ambientais como a acumulação de $\mathrm{CO}_{2}$ na atmosfera. Também não considera os efeitos degradantes para a sociedade que a acumulação de poluentes pode acarretar. Considera-se também que até o resultado das pesquisas levarem a estabilização da poluição (o que é conhecido para os agentes econômicos como poluição ótima), muito tempo terá passado e sendo assim, o equilíbrio proposto agora, pode não ser compatível com a poluição ótima futura.

Mueller (2000c, p.70) afirmou que:

[...] Existem duas categorias de políticas ambientais: políticas de comando e controle, apoiadas em leis, decretos, tratados, etc (a problematização referente ao acumulo de dióxido de carbono na atmosfera necessita da implantação dessa política de comando e controle); e políticas de estímulo de mercado - como por exemplo, os de direito negociáveis de poluir. A economia ambiental neoclássica tende a repudiar as políticas de comando e controle e a propor políticas de estímulo. Estas ofereceriam formas ágeis de controle de poluição e promoveriam a eficiência de estímulo. Trata-se, entretanto, de instrumentos úteis apenas para os casos de poluição de fluxo, principalmente as de impacto localizado.

Deve-se destacar que através da implantação de políticas de estímulos de mercado foram criados princípios como o do poluidor pagador (sendo que esta abordagem é bastante privilegiada pela economia ambiental neoclássica). $\mathrm{Na}$ concretização da implantação do princípio do poluidor pagador, seriam criadas formas de internalizar os custos impostos à sociedade, com a degradação que provocam. Assim, a empresa paga (talvez em forma de multas) tudo o que ela estiver poluindo ou degradando. 
As críticas feitas à teoria ambiental neoclássica da poluição não significam que esta abordagem não seja importante. Mas serve sim, para afirmar, que a mesma não abrange todos os níveis de poluição - principalmente os mais graves. Esta teoria suscita um debate de como enfrentar problemas causados por diversos tipos de poluição, principalmente aquelas cabíveis às políticas ou estratégias de médio prazo.

\section{Valoração Ambiental - Por que fazê-la?}

Com a consolidação da economia ambiental neoclássica, cada vez mais, está se desenvolvendo técnicas ou métodos mais sofisticados, na tentativa de medir elementos do meio-ambiente. A necessidade da economia ambiental em atribuir um valor (monetário) aos impactos ambientais tem como justificativa, motivos como: os de ordem prática (companhias de seguro, judiciário, entre outros, precisam de valores monetários para as indenizações), bem como a própria postura antropocêntrica (somada a hipótese ambiental) dessa corrente de pensamento (MUELLER, 2000c).

Imputando um valor para impactos causados ao meio-ambiente pelos agentes econômicos (consideram-se externalidades negativas), pode-se conseguir cada vez mais indicadores ou maneiras mais eficientes de alcançar o bemestar social. Normalmente, quando se considera as variações dos preços de mercado é por, principalmente, ter que valorar custos e benefícios ambientais de conseqüência do processo econômico. No entanto, a grande dificuldade é de se conseguir mensurar um bem público natural (não construído), sendo que o clima pode servir de exemplo a essa colocação.

A valoração ambiental tem como objetivo compreender o valor para visualizar as perdas, evitar as perdas e mediar as perspectivas futuras, ou seja, serve de instrumento de controle da degradação ambiental. Uma outra vantagem é que para uma sociedade capitalista, o racional envolve os ganhos e perdas do mercado. Assim, valorando os recursos naturais, insere-se este, na lógica capitalista.

Pereira (1999, p.22) afirmou que:

[...] a degradação ambiental, seja na forma de exploração de recursos naturais sem manejo, seja de poluição excessiva do ar e da água, por exemplo, geralmente ocorre porque os agentes do dano ignoram ou subestimam os custos da degradação para a sociedade. Há pois, uma divergência de interesses que não consegue ser resolvida no livre mercado per se. Justifica-se, portanto, a proposição da ação governamental na área ambiental para tentar fazer com que os custos ambientais (as externalidades do uso do meio ambiente pelo consumidor e pela firma) sejam internalizados nas funções de oferta (custo) e demanda.

Simplificando de forma bastante geral as muitas técnicas de mensuração ambiental, podem-se agrupá-las nas seguintes categorias: 1- técnicas que se valem diretamente de preços e valores de mercado, ou que se apóiam nas mudanças de produtividade causadas pela alteração ambiental; 2- métodos de 
mercados substitutos (métodos indiretos de valoração); 3- a valoração direta por métodos de mercados construídos (MUELLER, 2000c).

Existem, a princípio, três alternativas para a conformação de uma política ambiental: 10- O critério da proteção de risco zero; 20- O critério da melhor tecnologia; 30- O critério do equilíbrio entre os benefícios e os custos do controle da poluição. Destacar-se-á o terceiro critério, por ser o privilegiado pela economia ambiental neoclássica (MUELLER, 2000c).

A tentativa de compreender o equilíbrio entre os benefícios e os custos do controle da poluição, considera dois lados de extrema relevância: a posição que a sociedade assume ao desfrutar do bem-estar da produção e do consumo; e do outro lado, as conseqüências dessa mesma produção e consumo sobre o ambiente natural.

Para alcançar um equilíbrio entre os dois lados, existe a alternativa de estimar os custos e benefícios de cada um, para só assim, escolher a melhor alternativa. Mueller (2000c, pp.50-51) afirmou que

[...] Para tal, seria necessário à expressão de todos os possíveis
impactos favoráveis e desfavoráveis em termos monetários.
Entretanto, boa parte dos impactos positivos e negativos sobre o
meio-ambiente não podem, com facilidade, ser mensurados e
expressos em termos monetários; trata-se de bens e males que
não são transacionados em mercado. Na verdade, a despeito dos
avanços já feitos nas técnicas de valoração de custos e
benefícios ambientais dessa natureza, em muitos casos o custo
de efetuar as estimativas é elevado e a precisão das mesmas
não é muito grande.

Observa ainda que, a poluição ótima (para a economia ambiental neoclássica) é o resultado do confronto entre os benefícios da produção e consumo (que produzem poluição) e os custos dessa poluição gerada.

Para a economia neoclássica uma empresa polui por ser a poluição uma externalidade, ou seja, não há nenhum custo para a empresa ao poluir. Essa mesma empresa, sempre procuraria melhorar o lucro, mas nunca o bemestar da população. A maneira encontrada para que diminua a poluição é impondo uma taxa sobre a mesma. Assim, internalizaria o custo social causado pela poluição emitida.

No entanto, registra-se diversos problemas envolvendo as questões da valoração do meio ambiente. Um dos grandes destaques é que normalmente o interesse humano volta-se com maior intensidade a coisas de valor para ele (ou seja, que retorne ao homem de alguma forma - seja vantajoso). Na atualidade, a importância do ambiente natural é ainda algo que está sendo aprendido a passos lentos. Torna-se também interessante, destacar que o complexo ecossistema é tão extenso, que muitas informações ainda nem chegaram ao nosso conhecimento, e, talvez, nem irão chegar (a racionalidade humana pode destruílas antes).

Existem ainda, outros problemas na valoração ambiental. Por exemplo: a delimitação de quem são os recursos naturais (tem um dono?); quem são os responsáveis pela sua conservação/utilização?; Uma floresta ou uma bacia hidrográfica, com seus limites demarcados dentro de um determinado território, 
podem vir a ser denominadas como patrimônio nacional? (neste caso deve-se ter como exemplo o descuido da sociedade para tudo o que é público). Mas, e o clima? Quem é responsável por ele? E quando uma bacia hidrográfica faz parte de dois países? Qual deles irá responsabilizar-se pela sua conservação?

Margulis apud Martin (1999, p.38) fez alusão a algumas dificuldades na avaliação de valores ambientais, como:

1 - a tentativa de quantificação desses valores, uma vez que envolve o bem-estar das pessoas, sendo portanto subjetiva.

2 - relaciona-se não às limitações dos métodos econômicos, mas à falta de conhecimento técnico dos efeitos ambientais em questão. (...) caso se soubesse precisamente os efeitos ecológicos e a perda de produção associados a diferentes níveis de poluição, seria fácil para o economista atribuir valores monetários e determinar a quantidade ótima de produção, de controle e de poluição.

Infelizmente, a realidade da mensuração dos impactos ambientais é bastante complexa. Quando se fala em impacto ambiental não se deve pensar em um fator isolado, pois há interação entre as variadas formas de degradação, muitas vezes ainda não compreendidas. Assim, para a pesquisa, resta formular hipóteses (grande parte delas heróicas), com o intuito de transformar esses impactos em valores monetários.

\section{Uma referência a Economia da Sobrevivência}

A economia da sobrevivência não pode ser considerada uma corrente de pensamento como é a economia ambiental. No entanto, já existe um grupo de pesquisadores que organizam suas pesquisas (podendo assim ser chamada de "escola") enfatizando o bem-estar e garantindo as gerações futuras. Dessa forma, o compromisso dessa escola vai bem mais além que uma ou duas gerações (que não é de preocupação da economia ambiental neoclássica). (MUELLER, 2000d).

Um dos pontos de análise da economia da sobrevivência é a percepção e o cuidado que a população deve ter com o meio-ambiente, principalmente com alguns materiais retirados do ambiente natural, como os combustíveis fósseis existentes na natureza em quantidades limitadas. No entanto, não há nenhuma, ou quase isso, preocupação da sociedade em perceber que suas ações causam impactos que o sistema natural pode não suportar. Para esses pensadores, caso não ocorram mudanças radicais no comportamento social diante do sistema natural, o bem-estar da humanidade no futuro, ou mesmo sua sobrevivência, poderão ser seriamente comprometidos.

Outro ponto relevante é em relação ao funcionamento do sistema econômico relativo ao processo de produção e o consumo. Para a economia da sobrevivência, segundo Mueller (2000d, p.3).

[...] O sistema econômico aparece interagindo explicitamente com o meio-ambiente. Este fornece recursos naturais essenciais para a produção e recebe do sistema econômico fluxos e dejetos, 
de poluição, responsáveis por sua degradação. Dependendo do horizonte temporal que considere, e do seu viés analítico, a abordagem de uma dada corrente de pensamento econômico pode ir, desde o tratamento exclusivo de fenômenos que ocorrem dentro da caixa do sistema econômico, até uma abordagem integrada, que privilegie as inter-relações entre sistema econômico e o meio-ambiente.

Para a economia da sobrevivência e todas as suas variantes não são aceitos, em nenhuma hipótese, a liberdade econômica e o crescimento acelerado como estratégias para a sustentabilidade. As políticas de curto prazo de combate à degradação ambiental estão em segundo plano, dando maior importância ao desenvolvimento de estratégias de longo prazo.

A economia e o meio ambiente, portanto, são vistos interagindo como se fizessem parte de um sistema. Cada atitude humana, refletida na natureza, será de alguma forma cobrada do sistema econômico.

\section{A Relação do Clima e o Sistema Econômico}

Com a evolução das pesquisas no campo da climatologia geográfica e o reconhecimento pela economia ambiental da importância do meio ambiente para o pleno desenvolvimento social, constata-se o interesse por parte de diversos pesquisadores em compreender a verdadeira relação entre o clima e a economia. Observa-se também que a grande maioria dos trabalhos existentes nessa linha de pesquisa faz mais alusão ao segmento econômico agricultura.

Lockwaad apud Santos (1993, p.39) destacou que "[...] a importância dos estudos climatológicos tem aumentado nos últimos anos. Este crescimento verifica-se particularmente nos campos da agricultura e no uso da energia".

Ayoade (1988) considerou que os elementos climáticos podem ser objeto de um planejamento, pois os efeitos causados pelo clima, como a chuva, o calor e o frio, devem ser cada vez melhor aproveitados pelo homem. E, os efeitos negativos provocados pelo clima como, vendavais, enchentes, geadas e etc, devem ser mais minimizados (na escala do clima local, ou seja, no perímetro urbano), com a efetiva concretização do planejamento.

Ribeiro (1993) afirmou que principalmente durante os anos de 1970, surgiram dezenas de estudos abordando o zoneamento de culturas agrícolas.

[...] a climatologia geográfica pode contribuir para 0 entendimento da organização espacial da agricultura através da análise têmporo-espacial da oferta de insumo climático demandado pelas diferentes culturas de interesse da sociedade. Desta feita, pode-se afirmar que o campo de interesse da climatologia geográfica em relação à agricultura assenta-se, primordialmente, na variabilidade temporal (calendário agrícola) e espacial (zoneamento agroclimático) (de oferta do insumo climático). (RIBEIRO, 1993, p. 34)

Santos (1993) também trabalhou com as relações entre o clima e a agricultura. Para ela: 
[...] nas inter-relações entre agricultura e meio físico tem-se reconhecido que o clima se constitui no 'carro chefe' comandando grande parte do potencial agrícola de uma determinada área. Isso se verifica porque o homem possui os recursos técnicos para melhorar as condições dessa área, porém ainda não possui o controle das condições do tempo atmosférico, que em sua sucessão constitui o clima. (SANTOS, 1993, p. 39)

Bahls (1984), apresentou um estudo de análise da influência climática para o desenvolvimento da cultura de maçã no Brasil. Barrios (1987), analisou a produção agrícola na região de Presidente Prudente e sua relação com as chuvas; Tarifa (1973), aplicou as técnicas do balanço hídrico; Almeida (2000), estudou o grau da dependência da cultura de soja em relação às chuvas; Borsato (2001), pesquisou sobre a produtividade agrícola na Bacia do Rio Pirapó e sua relação com a dinâmica climática; Tommaselli (1992) estabeleceu um modelo mostrando as relações entre as deficiências hídricas sobre a queda da produção numa cultura de milho em Cambará e Londrina - PR.

É possível citar também alguns trabalhos que apresentam interesse em relacionar o clima e a economia, não tendo como objeto à agricultura. Por exemplo: Troppmair (1998, p.37), que relacionou as ocorrências de acidentes de trânsito com as neblinas, onde considerou que as neblinas são "[...] mais densas nos meses de inverno e mais acentuadas em campo aberto [...]" e que diminuíam "[...] gradativamente em direção ao centro da cidade". Também as madrugadas e o anoitecer "[...] são os períodos mais propícios à formação de neblinas". Justamente nesses períodos de incidências acentuadas de neblinas, ocorrem mais acidentes nas rodovias paulistas (no início e no fim de semana os índices são ainda mais acentuados); Costa (2001) fez referência à proliferação de Aedes aegypti com o clima no Noroeste do Paraná; Mendonça (1999), correlacionou os índices de criminalidade com as oscilações da temperatura, entre outros.

Os exemplos citados são uma pequena amostra de como pode ser desenvolvida uma pesquisa que relaciona um elemento natural (no caso específico o clima) e um elemento que faz parte da realidade da sociedade (agricultura, trânsito, proliferações de doenças, entre outros). Deve-se destacar que os primeiros indicativos de perdas de produção versus clima são facilmente percebidos entre as pessoas que trabalham diretamente no ambiente, como por exemplo, na agricultura, por isso, também o maior interesse a esse tipo de pesquisa.

Dentre diversas formas possíveis de correlacionar o clima e a economia (com alguns exemplos confirmados nos trabalhos anteriormente citados) foi constatado que o setor comercial de uma cidade também é cabível de investigação.

Esta idéia fundamenta-se nas questões que envolvem a construção da cidade, gerando também a "construção" de um clima "artificial". Este, por sua vez, tem a capacidade de interferir no comportamento dos diversos setores da sociedade. A quantidade de pessoas nas ruas fazendo compras, o tipo de produto consumido, o planejamento de compra de produtos por parte dos comerciantes, são alguns exemplos de atitudes que são constantemente moldados pelo tipo de tempo predominante. 


\section{Considerações finais}

Desta forma, considera-se que a valoração ambiental é uma corrente da economia ambiental que visa auxiliar no processo de integração das questões ambientais no sistema econômico. O princípio do poluidor pagador é um grande exemplo da concepção neoliberal desta corrente de pensamento. Ele parte da constatação de que os recursos ambientais são escassos e que o seu uso na produção e no consumo acarretam a sua redução e degradação. E, apenas considerando esses recursos no sistema de preços, torna-se possível o mercado mensurar a sua verdadeira escassez. Com o estabelecimento legal desse princípio a sociedade deixaria de arcar, em tese, com o ônus dos custos ambientais, impondo estes, aos verdadeiros responsáveis pela degradação.

$\mathrm{Na}$ atualidade, a agenda política do país, tem como fundamento retomar o crescimento, fortalecer a participação do país na economia global e reduzir as disparidades sociais. Uma das grandes questões que se coloca é a tentativa de equilibrar a economia de mercado juntamente com as estratégias de proteção social e ambiental.

Segundo estudos realizados pelo Ministério do Meio Ambiente (MMA, 2004), diante das constatações reais da presença das externalidades ambientais, tem-se maiores oportunidades para a intervenção governamental. Essa intervenção pode incluir instrumentos distintos, tais como: a consignação dos direitos de propriedade, o uso de normas ou padrões, os instrumentos econômicos, as compensações monetárias por danos, entre outros. E, ainda, segundo relatos do próprio Ministério do Meio Ambiente, apesar da intervenção governamental ser legítima, ela não é trivial. $E$, no que se refere aos aspectos ambientais, a intervenção ainda é mais complexa visto que os conhecimentos teóricos no sentido gerencial ainda são insuficientes. Por isso, a importância da apresentação de estudos que considerem ou inter-relacionam os dois objetos.

\section{Referências Bibliográficas}

ABREU, M. L. Uso de Modelos de Circulação Geral da Atmosfera para Simular o Clima e a Variabilidade Climática. In: SANT'ANNA NETO, J.L; ZAVATINI, J.A. Variabilidade e Mudanças Climáticas: Implicações Ambientais e Sócioeconômicas. Maringá: Eduem, 2000. Parte. II, p. 83-93.

ALDAZ, L. Caracterização parcial do regime de chuvas do Brasil. Rio de Janeiro: DEMET/OMM, 1971.

ALMEIDA, I.R. Variabilidade pluviométrica interanual e produção de soja no estado do Paraná. 2000. Dissertação (Mestrado) - FCT/UNESP, Presidente Prudente.

ANTUNES, P. de B. Direito Ambiental. Rio de Janeiro: Lúmen Júris, 2002.

$A Y O A D E$, J.O. Introdução à climatologia para os trópicos. Rio de Janeiro: Bertrand Brasil, 1988.

AZEVEDO, D. da C. Chuvas no Brasil: regime, variabilidade e probabilidade de alturas mensais e anuais. Brasília: DEMET/MA, 1974.

BAHLS, A. dos S. A Influência Climática na Cultura da Maçã. Boletim de Geografia, 
Maringá, v. 02, n.02, p. 48-51, janeiro, 1984.

BARRIOS, N.A.Z. Cotonicultura na região de Presidente Prudente: o regime e as variações de produção. 1987. Dissertação (Mestrado) - FFLCH, USP, São Paulo.

BORSATO, V.A. A dinâmica Climática e a Produtividade Agrícola na Bacia Hidrográfica do Rio Pirapó. 2001. Dissertação (Mestrado) - Universidade Estadual de Maringá.

BLANCO, H.G.; GODOY, H. Cartas das chuvas do Estado de São Paulo. Campinas: IAC/Secretária da Agricultura, 1967.

COSTA, M.A.R. A ocorrência do Aedes aegypti na região noroeste do Paraná: um estudo sobre a epidemia da dengue em Paranavaí. 2001. Dissertação (Mestrado) - FCT/UNESP, Presidente Prudente.

CUNHA, G.R. Aquecimento Global e Agricultura. Disponível em: <http://www.cnpt. embrapa.br>. Acesso em: jan. de 2003.

ENDLICH, A.M. Maringá e o Tecer da Rede Urbana Regional. 1998. Dissertação (Mestrado) - FCT/UNESP, Presidente Prudente.

GUADARRAMA, M.C.M. Ritmo pluvial e produção do arroz no Estado de São Paulo no ano agrícola de 1967/1968. Climatologia, São Paulo, 2, 1971.

GUJARATI, D.N. Ecconometria Básica. 3.ed. São Paulo: Makron Books, 2000.

IBGE (Instituto Brasileiro de Geografia e Estatística): Censo Econômico. Disponível em: <http://www.ibge.gov.br>. Acesso em: jan. de 2002.

IPARDES (Instituto Paranaense de Desenvolvimento Econômico e Social): Base de dados. Disponível em: <http://www.ipardes.gov.br>. Acesso em jan. de 2002.

MARTIN, E.S. Valoração dos Recursos Naturais. 1999. Relatório (Qualificação) IGCE, Rio Claro.

MARTINS, G. Análise da Variabilidade Termo-Pluviométrica e sua relação com o uso do solo no sudoeste do Paraná: 1970 a 1999. 2001. Dissertação (Mestrado) - FCT/UNESP, Presidente Prudente.

MENDONÇA, F. Ensaio Analítico da Correlação entre a Temperatura do ar e a Incidência de Criminalidade Urbana. 1999. Tese (Doutorado) - Curitiba, Paraná.

O clima urbano de cidades de porte médio e pequeno: aspectos teóricometodológicos e estudo de caso. In: SANT'ANNA NETO, J.L;ZAVATINI, J.A. Variabilidade e Mudanças Climáticas: Implicações Ambientais e Sócioeconômicas. Maringá: Eduem, 2000. Parte. III, p. 167-192.

MMA (Ministério do Meio Ambiente). Manual para Valoração Econômica de Recursos Ambientais. Disponível em: <http://www. Mma.gov.br/port/sbr/chm>. Acesso em: junh. 2004.

MONTEIRO, C. A. de F. Análise rítmica em climatologia. Climatologia, São Paulo, 1,1971 .

. O clima e a organização do espaço no Espaço de São Paulo: problemas e perspectivas. Série Teses e Monografias, São Paulo, 28, 1976.

MORAN, Emílio F. Adaptabilidade Humana: Uma Introdução à Antropologia Ecológica. São Paulo: Universidade de São Paulo, 1994.

MUELLER, C.C.; NOGUEIRA, J.M. Economia e Meio Ambiente. UNB, Brasília, 2000.

; A Economia Ambiental Neoclássica. UNB, Departamento de Economia, 2000c. In: MUELLER, C.C.; NOGUEIRA, J.M. Economia e Meio Ambiente. UNB, Brasília, 2000. p. 2-4;50-51;67; 70.

; Economia do Meio Ambiente e a Preservação das Oportunidades das Gerações Futuras - A Economia da Sobrevivência. UNB, Departamento de Economia, 2000d. In: MUELLER, C.C.; NOGUEIRA, J.M. Economia e Meio Ambiente. UNB, Brasília, 2000. p.3. 
PEREIRA, R.R. Análise Custo-Efetividade na Gestão Econômica do Meio Ambiente. 1999. Dissertação (Mestrado em Gestão Econômica do Meio Ambiente) - UNB, Brasília. Disponível em: <http://www. Unb.br/ih/eco/nepama/mestrado.htm/>. Acesso em: abr. 2002.

QUEIROZ, D.R.E. O Mapa e seu papel de comunicação - Ensaio Metodológico de Cartografia Temática em Maringá - PR. 1994. Dissertação (Mestrado) - FFLCH, USP, São Paulo.

RIBEIRO, A.G. A Climatologia Geográfica e a Organização do Espaço Agrário. Boletim de Geografia Teorética. Rio Claro, SP, v.23, n.34-38, p.39-45, 1993.

SANT'ANNA NETO, J.L. Ritmo Climático e a Gênese das Chuvas na Zona Costeira Paulista. 1990. Dissertação (Mestrado) - FFLCH, USP, São Paulo.

As Chuvas no Estado de São Paulo. 1995. Tese (Doutorado) - FFLCH, USP, São Paulo.

. As chuvas no Estado de São Paulo: A variabilidade pluvial nos últimos 100

anos. In: SANT'ANNA NETO, J.L; ZAVATINI, J.A. Variabilidade e Mudanças Climáticas: Implicações Ambientais e Sócioeconômicas. Maringá: Eduem, 2000. Parte. II, p. 95-119.

SANTOS, M.J.Z. dos. Tendência das Chuvas no Nordeste paulista e problemas ligados com as pesquisas em Climatologia agrícola. Boletim de Geografia Teorética. Rio Claro, SP, n.45-46, p.39-45, 1993.

SORRE, M. Lês Fondaments de la Geographie Humaine - (lês fondements biologiques - Le climat). Paris: Libr. Armand Colin, 1951.

SPIEGEL, M.R. Estatística. 3a ed. São Paulo: Makron Books, 1993.

SUDO, H. Processos Erosivos e Variabilidade Climática. In: SANT'ANNA NETO, J.L; ZAVATINI, J.A. Variabilidade e Mudanças Climáticas: Implicações Ambientais e Sócioeconômicas. Maringá: Eduem, 2000. Parte. II, p. 121-145.

TARIFA, J.R. Sucessão de tipos de tempo e variação do balanço hídrico no extremo oeste paulista. Série Teses e Monografias, São Paulo, 8, 1973.

TITARELLI, A.H.V. A onda de frio de abril de 1971 e sua repercussão no espaço geográfico brasileiro. Climatologia, São Paulo, 4, 1972.

TOMASELLI, J.T.G. Deficiências Hídricas no Solo e Épocas de Plantio de Milho (Zea mays) em Cambará e Londrina - PR. 1992. Dissertação (Mestrado) Escola Superior de Agricultura Luiz de Queiroz, USP, Piracicaba.

TROPPMAIR, H. Condições Geoambientais, Ocorrência de Neblina e Acidentes em Rodovias Paulistas. Geografia, Rio Claro, v.23, n.3, p.5-96, dez.1998.

VILELA, R.J. Variações Climáticas Anuais e Produção Agrícola. Caderno de Ciências da Terra, USP, p.1-9, 1973.

ZAVATINI, J.A. Variações do ritmo pluvial no oeste de São Paulo e norte de Paraná: eixo Araçatuba/Presidente Prudente/Londrina. 1983. Dissertação (Mestrado) - FFLCH, USP, São Paulo. 